\title{
SOROEPIDEMIOLOGIA DE ROTAVÍRUS EM UMA POPULAÇÃO INFANTIL, GOIÂNIA, GOIÁS, BRASIL (1)
}

\author{
Ricardo ISHAK (2, 3), Alexandre da Costa LiNhaReS (4), Yvone GabBay (4), Marluísa $O$. $G$. \\ ISHAKK $(3,5)$ e Divina D. P. CARDoso (6)
}

\begin{abstract}
R E S UMO
Amostras de soro de 125 crianças, com idades entre 0 e 10 anos, da popuiação de Goiânia, Goiás, Brasil, geraram um índice de prevalência de anticorpos para rotavírus (ensaio imunoenzimático) de $82,4 \%$. Aparentemente, o maior risco de infecção pelo vírus se dá no grupo de 1 a 3 anos. Não existe diferença de infecção de acordo com o sexo. Informações soroepidemiológicas a nível nacional, são de grande importância para o melhor conhecimento do comportamento do vírus na população em risco, principalmente quando existe a possibilidade de uma futura imuno-profilaxia. O teste imuno-enzimático em comparação com a contraimuno-eletro-osmoforese, mostrou-se mais sensível para a detecção de anticorpos para rotavírus.
\end{abstract}

\section{N T ROD U G Ã O}

A partir da descrição inicial, em 1973, por BISHOP \& col.2, na Austrália, do papel dos rotavírus em casos de diarréia infantil, esses agentes tem sido largamente assinalados em todas as populações até então examinadas $3,6,9$, 10,13,17,18,22. Em países de clima temperado tem sido mostrado que as infecções por rotavírus acometem, preferencialmente, crianças na faixa etária de 0-5 anos 4,7,12.

No Brasil, os rotavírus tem sido descritos em associação com casos de gastrenterite aguda em porcentuais que variam de $21 \%$ a $33 \%$, de acordo com o grupo populacional e a faixa etária examinada, mostrando que existe uma diferença na frequiência de participação desse agente nos casos de diarréia aguda 1,6,15,16. Estudos preliminares de prevalência de anticorpos para rotavírus em nosso País, já demonstraram positividade em cerca de $61 \%$ na população de $0-10$ anos $^{4}$.

Amostras de soro de 125 crianças de $0-10$ anos, da cidade de Goiânia, Goiás, Brasil, foram testadas quanto a presença de anticorpos para rotavírus. Procurou-se ainda comparar os resultados da contraimuno-eletro-osmoforese e do ensaio imuno-enzimático, como técnicas sorológicas para detecção de anticorpos para este vírus.

\section{MATERIAIS E METODOS}

\section{População e o meio ambiente}

As 125 amostras de soro foram obtidas por punção venosa, em 1979, de crianças sem diar. réia, atendidas no Laboratório de Patologia Clí-

(1) Suporte financeiro CNPq (Processo n.० 40.3228/79)

(2) Universidade Federal do Pará. Centro de Ciências Biológicas. Departamento de Patologia. 66.000 - Belém - Pará, Brasil

(3) Endereço atual: London School of Hygiene and Tropical Medicine. Department of Medical Microbiology. Keppel Street. London WC1 E $7 \mathrm{HT}$ - England

(4) Instituto Evandro Chagas. Caixa Postal 621. 66,000 - Belém - Pará

(5) Bolsista CAPES

(6) Universidade Federal de Goís. Instituto de Patologia Tropical. Caixa Postal 131 - 74.000 - Goiânia - Goiás, Brasil 
ISHAK, R.; LINHARES, A. da C.; GABBAY, Y.; ISHAK, M. O. G. \& CARDOSO, D. D. P. - Soroepidemiologia de rotavírus em uma população infantil, Goiânia, Goiás, Brasil. Rev. Inst. Med. trop. São Paulo 26:280-284, 1984.

nica do Hospital das Clínicas da Universidade Federal de Goiás (UFGo), no Laboratório de Virologia do Instituto de Patologia Tropical da UFGo e laboratórios de análises clínicas privados da cidade de Goiânia. Os soros foram preservados por congelamento a $-20^{\circ} \mathrm{C}$ até o momento do uso. A distribuição dos soros, de acordo com a faixa etária, pode ser apreciada na Tabela I.

A população de Goiânia, está localizada em um ponto de transição climática no Brasil Central, em uma altitude média de 400 metros entre os paralelos $16^{\circ}$ e $17^{\circ}$ de latitude sul e $49^{\circ}$ e $50^{\circ}$ de longitude Oeste ${ }^{8}$. Esta localização propicia um clima que apresenta variações sazonais no decorrer do ano, com temperaturas de calor e frio bem definidas.

\section{Antígeno}

A cepa utilizada foi obtida através do Dr. T.H. Flewett (East Birmingham Hospital, Birmingham, Inglaterra) como uma suspensão de fezes de um bezerro ("gnotobiotic"). Este material foi diluido a 1:400 em solução salina fisiológica e, com auxílio de sonda gástrica, foram inoculados $5 \mathrm{ml}$, via oral, em novo bezerro (não "gnotobiotic") antes de receber o colostro. Espécimes fecais deste animal foram usados como antígeno para os testes sorológicos abaixo descritos, após um processo em que suspensões de fezes a $20 \%$ (em solução salina) foram homogeneizadas por sonicação durante $1,5 \mathrm{mi}$ nuto em aparelho Ultra Sonics, modelo W-185-D, e clarificadas por centrifugação, a $5000 \mathrm{rpm}$ durante 30 minutos.

\section{Contraimuno-eletro-osmoforese}

A técnica usada foi a de SPENCE \& col. ${ }^{21}$. Tris barbital, $0.01 \mathrm{M}, \mathrm{pH}$ 8.9, filtrado em membrana de $22 \mathrm{~nm}$, foi usado como solução tampão do teste. Lâminas comuns de microscopia, previamente desengorduradas $\mathrm{em}$ álcool absoluto, foram cobertas com $0,5 \mathrm{ml}$ de uma mistura de uma parte de uma solução estoque de agarose (Seakem, Marine Colloids Inc, USA) a $2 \%$ (em água destilada) e duas partes de água destilada. Após solidificação, foi adicionada uma segunda camada de $2 \mathrm{ml}$ da mistura, em quantidades iguais, de agarose a $2 \%$ e solução tampão. As lâminas foram mantidas a $4^{\circ} \mathrm{C}$ até adquirirem consistência. Orifícios de aproximadamente $1,5 \mathrm{~mm}$ de diâmetro e de $1 \mathrm{~mm}$ de profundidade foram feitos na camada de agarose com o auxílio de tubos capilares. Os soros, diluidos a 1:10 e 1:40 em tampão salina fosfato (PBS), foram levados a reagir com o antígeno por 90 minutos sob ação de uma corrente de 150 volts em um tanque de eletroforese Gelman. Após esse período, as lâminas foram imersas em solução salina esteril por uma noite e, a seguir, em solução de ácido tânico a $1 \%$ por 90 minutos. Os resultados positivos foram deter. minados pela presença de linhas de precipitação entre os orificios contendo o antigeno e os soros testes.

\section{Ensaio imuno-enzimático}

O procedimento utilizado foi basicamente 0 descrito por VOLLER \& col. ${ }^{26}$. Soro de coelho anti-rotavírus, diluido a 1:10.000 em solução tampão de carbonato-bicarbonato, pH 6.9 ("Coating buffer"), foi colocado em cada orifício (100 $\mu \mathrm{I})$ de microplacas de poliestireno, as quais foram. levadas a incubação a $4^{\circ} \mathrm{C}$ por uma noite. Após seis lavagens (de 3 minutos cada uma) em PBS, pH 7.4, contendo Tween 20 a uma concentração final de $0,1 \%, \vee / v,(P B S / T)$, foi adicionado $75 \mu 1$ (por orifício) de PBS/T acrescido de EDTA (concentração final de $0,01 \mathrm{M}$ ) e $25 \mu 1$ de suspensão de antígeno de rotavírus. As placas foram incubadas a $4^{\circ} \mathrm{C}$ por uma noite e a seguir lavadas seis vezes em PBS/T. Em seguida, adicionou-se $100 \mu \mathrm{l}$ do soro teste em questão, incubou-se a $37^{\circ} \mathrm{C}$ por 3 horas e novamente procedeu-se mais seis lavagens em PBS/T. Um volume de $100 \mu 1$ de soro anti-IgG humana conjugado a fosfatase alcalina foi adicionado, incubou-se por 1,5 hora sucedendo-se novo ciclo de lavagens em $\mathrm{PBS} / \mathrm{T}$. Substrato enzimático de fosfato de para-nitrofenil (Sigma, USA) em dietanolamina a $10 \%, \mathrm{v} / \mathrm{v}, \mathrm{pH} 9.8$, foi adicionado (100 $\mu 1)$ e deixado reagir por 20 minutos a $37^{\circ} \mathrm{C}$. A reação foi bloqueada através da adição de $50 \mu \mathrm{l}$ de solução $3 \mathrm{M}$ de hidróxido de sódio. A leitura, em densidade óptica, foi realizada em micro-espectrofotômetro (Flow, ELISA-reader, Multiskan) com filtro de $405 \mathrm{~nm}$. As amostras com valor maior do que 2,1 na relação valor positivo/negativo, $\mathrm{P} / \mathrm{N}$ (28), foram consideradas positivas. 
ISHAK, R.; LINHARES, A. da C.; GABBAY, Y.; ISHAK, M. O. G. \& CARDOSO, D. D. P. - Soroepidemiologia de rotavírus em uma população infantil, Goiânia, Goiás, Brasil. Rev. Inst. Med. trop. São Paulo 26:280-284, 1984.

\section{RESULTADOS}

Tomando-se o resultado obtido através do teste imuno-enzimático podemos apreciar na Tabela I prevalência de anticorpos para rotavírus de $82,4 \%$. E possível evidenciarmos uma subida gradual na positividade de anticorpos, na medida em que se aumenta a faixa etária examinada. Assim é que, $52,4 \%$ (11/21) já possui imunidade para rotavírus ao completar 12 meses de idade, índice este que sobe para $70 \%$ (42/60) ao final dos cinco primeiros anos de vida. O último grupo examinado mostra resultados negativos em apenas $10 \%$, elevando o porcentual de infecção na primeira década de vida para mais de $80 \%$. Através das colunas do índice de porcentual de positividade acumulado e pela diferença entre cada classe, nota-se que a maior parte das infecções por rotavírus se dá na faixa de 6 meses a 5 anos, sendo o grupo de 1.3 anos, o de maior risco epidemiológico. Aparentemente, não existe diferença de infecção de acordo com o sexo.

T A B E L A I

Prevalência de anticorpos para rotavírus, distribuído por idade, em uma população de crianças de Goiânia, Goiás, Brasil (1)

\begin{tabular}{lcccc}
\hline Idade & $\begin{array}{c}\text { População } \\
\text { examinada }\end{array}$ & $\begin{array}{c}\text { Presença de } \\
\text { anticorpos }(\%)\end{array}$ & $\begin{array}{c}\text { Porcentual } \\
\text { positivo } \\
\text { acumulado }\end{array}$ & $\begin{array}{c}\text { Diferença } \\
\text { do }\end{array}$ \\
\hline $0-6 \mathrm{~m}$ & 13 & $6(46,2)$ & 46,2 & 5,2 \\
$6-12 \mathrm{~m}$ & 8 & $5(62,5)$ & 52,4 & 13,4 \\
$1-3 \mathrm{a}$ & 20 & $16(80,0)$ & 65,8 & 4,2 \\
$3-5 \mathrm{a}$ & 19 & $15(78,9)$ & 70,0 & 5,9 \\
$5-7 \mathrm{a}$ & 19 & $18(94,7)$ & 75,9 & 3,9 \\
$7-9 \mathrm{a}$ & 20 & $19(95,0)$ & 79,8 & 2,6 \\
$9-11 \mathrm{a}$ & 26 & $24(92,3)$ & 82,4 & 2 \\
\hline Total & 125 & $103(82,4)$ & &
\end{tabular}

(1) Anticorpos medidos através do ensaio imuno-enzimático; para detalhes técnicos veja o texto.

Na Tabela II, o teste imuno-enzimático é comparado com a CIEOF, quanto a sensibiliclade na detecção de anticorpos. Os métodos concordam em $31,1 \%$ das situações (16 positivos e 17 negativos, por ambos os métodos, dos soros examinados). A primeira técnica, entretanto, revelou-se mais sensivel, já que 73 amos tras, negativas por CIEOF, resultaram positi vas.

T A B E I A II

Comparação dos testes imuno-enzimático e contraimunoeletro-osmotorese (CIEOF) na deteç̧ão de anticorpos para rotavirus

\begin{tabular}{lcccc}
\hline \multirow{2}{*}{$\begin{array}{l}\text { Imuno- } \\
\text { enzimático }\end{array}$} & \multirow{3}{*}{ CIEOF } \\
\cline { 2 - 5 } & Positivo & Negativo & \\
\hline Positivo & 16 & 73 & 89 \\
Negativo & 0 & & 17 & 17 \\
\hline Total & 16 & & 90 & 106 \\
\hline
\end{tabular}

\section{DISGUSSÃO}

O uso de informações geradas através de soroepidemiologia descritiva, torna-se, atual. mente, do mais alto interesse em nosso Pais, quando se evidenciam esforços para o controle de diversas doenças infecciosas. Dentro deste painel, se incluem as informações sobre a prevalência dos rotavírus. E importante o conhecimento das possíveis variações regionais da ocorrência deste agente em um momento em que os esforços estão voltados para a produção de vacinas $20,23,27$. O uso de medidas profiláticas devem ser sempre precedidas de dados sobre o grupo populacional epidemiologicamente em risco 5 .

Através da Tabela I, torna-se evidente que o grupo de 6 meses -5 anos é o mais envolvido por infecções pelo(s) rotavirus. Tomando-se por base a coluna sobre a diferença do porcentual positivo acumulado, o grupo de 1.3 anos, é o que, aparentemente, mais entra em contato com o vírus na faixa etária mais próxima do nascimento. O porcentual do grupo até 6 meses de idade, talvez reflita a presença de fatores antivirais específicos e inexpecíficos adquiridos através do aleitamento materno 19,24,25. Por outro lado, o aumento na faixa etária seguinte, talvez represente a ausência de tais fa- 
ISHAK, R.; LINHARES, A. da C.; GABBAY, Y.; ISHAK, M. O. G. \& CARDOSO, D. D. P. - Soroepidemiologia de rotavírus em uma população infantil, Goiânia, Goiás, Brasil. Rev. Inst. Med. trop. São Paulo 26:280-284, 1984.

tores em um grupo que já não recebe o aleitamento natural, somados as condições de higiene da população em geral, visto que a diferença de porcentual positivo acumulado não é diferente dos grupos de 3-7 anos.

No programa de aplicação de vacinas para rotavírus, é importante que informações nacionais sejam geradas para confirmar, ou não, os dados ora apresentados. Et crucial que seja estimulado o conhecimento da participação desse agente na população infantil, visto que após os 9 anos, mais de $80 \%$ das crianças já foram infectadas pelo(s) rotavírus. É importante ainda, que exista uma participação do clínico, em especial do pediatra, junto ao laboratório de diag. nóstico de viroses, para uma maior caracteriza. ção dos aspectos epidemiológicos da distribuição de rotavírus, a fim de que se alcance o pleno sucesso em programas futuros de profilaxia 11.

Quanto aos testes sorológicos, a reação imunoenzimática foi comparada com a CIEOF. Ambos os testes requerem perícia técnica, se equivalem em economia de reagentes, segurança ao manipulador, acessibilidade de equipamentos e preços variáveis, sendo diferente apenas a CIEOF em termos de tempo de realização. Enquanto que para a deteç̧ão de antígeno nas fezes de pacientes com diarréia os dois testes apresentam resultados não muito discrepantes ${ }^{15}$, na detecção de anticorpos para rotavírus, o teste imuno-enzimático confirmou ser um método mais prático e mais sensívei, tendo, talvez, como unico argumento contrário, o custo do micro-es pectrofotômetro para a leitura das reações em placas.

\section{SUMMARY}

\section{Seroepidemiology of rotavirus in a children po- pulation, Goiânia, Goiás, Brazil.}

A sample of 125 sera from children aged 0-10 years old from Goiânia, Goiás, Brazil, yielded an $82.4 \%$ prevalence rate of antibodies to rotavirus (through an enzyme immunoassay). In this study, the 1-3 year old group shows the highest risk of infection 'with rotavirus. No sex difference was evident. Regional seroepidemioIogical data is of the utmost importance in order to identify the behaviour of the virus in the population at risk, specially with the advent of a vaccine for the agent. The enzyme imu. noassay test was compared to counterimmunoelectro-osmophoresis and was shown to be more sensitive for the detection of antibodies.

\section{REFERENGIAS BIBLIOGRAFICAS}

1. BALDACCI, E. R.; CANDEIAS, J. A. N.; BREVIGLIERI, J. C. \& GRISI, S. J. E. - Etiologia viral e bacteriana de casos de gastroenterite infantil: uma caracterização clínica, Rev. Saúde Públ. 13: 47-53, 1979.

2. BISHOP, R. F.; DAVIDSON, G. P.; HOLMES, I. H. \& RUCK, B. J. - Virus particles in ephitelial cells of duodenal mucosa from children with acute non. bacterial gastroenteritis. Lancet 2: 1281-1283, 1973.

3. BISHOP, R. F.; DAVIDSON, G. P.; HOLMES, I. H. \& RUCK, B. J. - Detection of a new virus by elec; tron microscopy of faecal extracts from children with acute gastroenteritis. Lancet 1: 149-151, 1974.

4. BLACKLOW, N. R.; ECHEVERRIA, P. \& SMITH, D. H. - Serological studies with reovirus-like enteritis agent. Infection \& Immunity 13: 1536-1566, 1976.

5. CAMARGO, M. E. - Laboratory diagnosis for seroe. pidemiology of Chagas' Disease. Anais do Congresso Internacional sobre Doença de Chagas. Rio de Janeiro, R.J., Brasil, 1979, pp. H7-H9.

5. CANDETAS, J. A. N.; ROSENBURG, C. P. \& RACZ, M. L. - Identificaçäo por contraimunoeletroforese de rotavirus em casos de diarréia infantil. Rev. Saúde Públ. 12: 99-103, 1978

7. ELIAS, M. M. - Distribution of titres of rotavirus antibodies in aifferent age groups. J. Hyg. (Cambridge) 79: $365-373,1977$.

8. Enciclopédia dos Municípios Brasileiros. IBGE. Rio de Janeiro, R.J., Brasil, 36: 1858.

9. FLEWETT, T. H.; BRYDEN, A. S. \& DAVIES, H. Virus particles in gastroenteritis. Lancet 2: 1497, 1973.

10. FLEWETT, T. H. \& WOODE, G. N. - The rotavirus, brief review. Arch. Virology 57: 1-23, 1978.

11. ISHAK, $R$. - A racionalidade do correto diagnóstico đas viroses: imoortância e função na área de saúde humana. Rev. Latino-Americana Microbiol. 23: 245-248, 1981.

12. KAPIKIAN, A. Z; KIM, H. W; WYATT, R. G. ; CLINE, W. L.; ARROBIO, J. O.; BRANDT, C. D.; RODRIGUEZ, W. J.; SACK, D. A.; CHANOCK, R. M. \& PARROTT, R. H. - Human reovirus-like agent as the major pathogen associated with winter gastroenteritis in hospitalized infants and young children. New Engl. J. Med, 294: 965-972, 1976.

13. KAPIKIAN, A. Z.; KIM, H. W.; WYATT, R. G.; RODRIGUEZ, W. J.; ROSS, S.; CLINE, W. I.; PARROTT, R. H. \& CHANOCK, R. M. - Reovirus-like agent in stools: association with infantile diarrhea 
ISHAK, R.; LINHARES, A.: da C.; GABBAY, Y.; ISHAK, M. O. G. \& CARDOSO, D. D. P. - Soroepidemiologia de rotavirus em uma população infantil, Goiânia, Goiás, Brasil. Rev. Inst. Med. trop. São Paulo 26:280-284, 1984.

and development of serological tests. Science 185: 1049-1053, 1974.

14. LAMPE, E.; LIBERTO, M. I. M.; VAZ, M. G. S.; MATTOS, I. G. \& vONHUBINGER, M. G. - Levantamento sorológico para rotavírus, através de imunofluorescência indireta (IFI). Comunicação apresentada no 11.0 Congresso Brasileiro de Microbiologia, Florianópolis, S.C., Brasil, 1981.

15. LINHARES, A. C.; MONÇÃO, H. C.; GABBAY, Y. B.; ARAÚJO, V. L.; SERRUYA, A. C. \& LOUREIRO, E. C. B. - Acute diarrhoea associated with rotavirus among children living in Belém, Brazil. Trans. Royal Soc. Trop. Med. \& Hyg. 77: 384-390, 1983.

16. IINHARES, A. C. \& PINHEIRO, F. P. - Gastroente rites por rotavirus. In: Doenças Infecciosas e Parasitárias. Veronesi, R. (ed.). $7^{\text {a }}$ edlição. Rio de Janeiro, Guanabara Koogan, 1982, pp. 92-94.

17. LINHARES, A. C.; PINHEIRO, F. P.; FREITAS, R. B.; GABBAY, Y. B.; SHIRLEY, J. A. \& BEARDS, G. M. - An outbreak of rotavirus diarrhea among a nonimmune, isolated South American Indian community. Amer. J. Epidemiol. 113: 703-710, 1981.

18. LINHARES, A. C.; PINHEIRO, F. P.; SCHMETZ, C.; MULLER, G. \& PETERS, D. - Duovírus (rotavírus) $\mathrm{em}$ Belém do Pará, Brasil. Rev. Inst. Med, trop. São Paulo 19: 278-279, 1977.

19. MCLEAN, B. S. \& HOLMES, I. H. - Effects of an. tibody, trypsin and trypsin inhibitors on susceptibility of neonates to rotavirus infection. J. Clin. Microbiol. 13: 22-29, 1981.

20. SOULEBOT, J. P.; DAUVERGNE, M.; BRUN, A. \& ESPINASSE, J. - Protection of newborn calf against gastroenteritis with inactivated rotavirus vaccine. Comunicação apresentada nà Primeira Conferência Internacional sobre o Impacto das Doenẹas Virais no De. senvolvimento dos Paises Latino-Americanos e da Região do Caribe. Rio de Janeiro, R.J., Brasil, 1982.

21: SPENCE, L.; FAUVEL, M.; PETRO, R. \& BLOCK, S. - Comparison of counterimmuno--electrophoresis and electron microscopy for laboratory diagnosis of human reovirus-like agent associated infantile gastroenteritis. J. Clin. Microbiol. 5: 248-249, 1977.

22. SUZUKI, H. \& KONNO, T. - Reovirus-like particles in jejunal mucosa of a japanese infant with acute infectious non-bacterial gastroenteritis. Tokohu J. Exper. Med. 115: 199-211, 1975.

23. THIND, I. S. - Immunization as a public policy implications for developing countries. Comunicação apresentada na Primeira Conferência Internacional sobre o Impacto das Doenças Virais no Desenvolvimento dos Países Latino-Americanos e da Região do Caribe. Rio de Janeiro, R.J., Brasil, 1982.

24. TOTTERDELL, B. M.; CHRYSTIE, I. L. \& BANATVALA, J. E. - Cord blood and breats milk antibodies in neonatal rotavirus infection. Brit. Med. J. 1: 828830,1980 .

25. TOTTERDELL, B. M.; NICHOLSON, K. G.; MAC LEOD, J.; CHRYSTIE, I. L. \& BANATVALA, J. E. - Neonatal rotavirus infection: role of lacteal neutralising alpha, anti-trypsin and nonimmunoglobulin an. tiviral activity in protection. J. Med. Virology 10: $37-44,1982$

26. VOLLER, A.; BARTLETT, A. \& BIDWELL, D. - Enzyme immunoassays with special reference to ELISA technique. J. Clin. Path. 31: 507.520, 1978.

27. WYATT, R. G.; KAPIKIAN, A. Z.; THORNHILL, T. S.; SERENO, M. M.; KIM, H. W. \& CHANOCK, $R$. M. - In vitro cultivation in human fetal intestinal organ culture of a reovirus-like agent associated with nonbacterial gastroenteritis in infants and children. $\mathbf{J}$. Infect. Dis. 130: 523-528, 1974.

28. YOLKEN, R. H.; KIM, W. H.; CLEM, T.; WYATT, R. G.; CHANOCK, R. M.; KALIKA, A. R. \& KAPFKIAN, A, Z. - Enzyme-linked immunosorbent assay (ELISA) for detection of human reovirus-like agent of infantile gastroenteritis. Lancet 2: 263-267, 1977.

Recebido para publicaçăo em 21/12/1983. 